\title{
Diversity of Grain Quality Characteristics of Traditional Rice (Oryza sativa L.) Varieties in Sri Lanka
}

\author{
B.D.R. Prashantha ${ }^{3}$ \\ Postgraduate Institute of Agriculture \\ University of Peradeniya \\ Sri Lanka
}

S.P. Rebeira ${ }^{*}$, H.A.M. Wickramasinghe ${ }^{1}$, W.L.G. Samarasinghe ${ }^{2}$ and

\begin{abstract}
Physical properties of rice (Oryza sativa L.) grain namely, kernel length, width, milling recovery, head grain yield, and physicochemical properties including amylose content, gelatinization temperature, gel consistency and volume expansion ratio were analyzed for 21 selected traditional rice varieties. The brown rice and hull percentages varied from $77-80 \%$ and $20-23 \%$, respectively while the head rice yield varied between 55$73 \%$ for raw rice milling except for the variety Kuruluthuda. The volume expansion over cooking was more than 2.6 times compared to uncooked rice in all the varieties except for Kuruluthuda and Masuran. The gelatinization temperature (GT) was determined based on alkali spreading score and the majority of the rice varieties evaluated showed intermediate GT $\left(70-74{ }^{\circ} \mathrm{C}\right)$. The rice varieties Madathawalu, Pokkali, Maa Wee, Gonabaru, Inginimitiya and Dular showed low GT values $\left(55-69^{\circ} \mathrm{C}\right.$ ). No variety was found with a high GT (above $74{ }^{\circ} \mathrm{C}$ ). Intermediate amylose content $(A C)$ was observed in the majority of varieties except Suduru Samba that recorded a low AC while Herath Banda and Kalu Heenati recorded high ACs. Pachchaperumal and Maa Wee reported a low AC close to intermediate AC. The gel consistency (GC) was highly varied among the selected varieties. Usually soft GC is preferred over hard GC by the consumers. Rice varieties Herath Banda, Wanni Dahanala, Rathal, Hondarawalu, Kuruluthuda, Deveraddiri, Sulai and Masuran were identified as the soft GC varieties.
\end{abstract}

Keywords: Eating and cooking quality, physical properties, physicochemical properties, traditional rice

\section{INTRODUCTION}

Rice production in Sri Lanka has grown remarkably during last few decades and thus at present, Sri Lanka remains at the self-sufficiency level. Rice being the staple food with a per-capita consumption of $114 \mathrm{~kg}$ per year, it plays a major role in nutritional status of the whole population in the country. Present programme of rice production have been mainly targeted on fulfillment of the national demand. Breeding efforts at the national level have resulted in high yielding varieties with resistance to different biotic and abiotic stresses (Wickramasinghe \& Noda, 2008). But, with the achievement of production goals, acquisition of better intrinsic quality of rice has been identified as one of the possible avenues and

\footnotetext{
Department of Agriculture Biology, Faculty of Agriculture, University of Peradeniya, Sri Lanka

Rice Research and Development Institute, Bathalagoda, Sri Lanka

Department of Food Science and Technology, Faculty of Agriculture, University of Peradeniya, Sri Lanka

Corresponding author: hamangalikawickramasinghe@gmail.com
} 
challenges of the next decade (Abeywickrama et al., 2010). With the increasing awareness, people tend to be more health conscious and more interested on nutritional quality of food. Therefore, indigenous rice varieties have a considerable demand in local and international markets. Commercial rice growers and rice exporters have already created a niche market among the local and international consumers owing to their nutritional and medicinal properties recognized through the indigenous knowledge. There were over four hundred different traditional varieties of rice grown in the country, each with different nutrient values and cooking and eating characteristics (Abesekara et al., 2008).

Although consumer acceptability essentially depends on grain quality characteristics, the quality characteristics of traditional rice varieties are not published to expand their market potentials locally and internationally. Only a few studies are found in literature evaluating the quality characteristics of traditional rice (Wickramasinghe \& Noda, 2008; Abesekara et al., 2013). However, the available information is not sufficient enough to gain an overall idea on the quality characteristics of the grain and their potential in international rice markets and their potential applications in future varietal improvement programmes. This demands more elaborated studies to identify the diversity of grain quality characteristics of traditional rice varieties.

Rice grain quality is determined by its physical and physicochemical properties. Physical properties include kernel size, shape, milling recovery, degree of milling and grain appearance (Cruz \& Khush, 2000). Physical quality has a great importance in commercial rice production as it highly influences on the final output as well as the consumer demand which are directly contribute to the economic profitability of the grower and miller.

Physicochemical properties of rice are determined based on amylose content, gel consistency and gelatinization temperature (Rohilla et al., 2000). In rice, eating and cooking qualities are mainly controlled by the physicochemical properties which greatly influence the consumer's affinity (Rohilla et al., 2000). Therefore, eating and cooking quality can be considered as a vital intrinsic quality component of rice grains that have to be focused in future rice breeding programmes of the country to meet market demands at both local and international level. Volume expansion over cooking is another quality parameter which influences the edible volume which is the final output after cooking.

Therefore, this study was conducted to evaluate the diversity of rice grain quality of selected traditional rice varieties based on physical and physicochemical properties that will provide highly important information for future rice breeding programmes as well as for consumers.

\section{MATERIALS AND METHODS}

Twenty one selected traditional rice varieties were grown at the Rice Research and Development Institute (RRDI) Bathalagoda in Maha 2012/2013 under similar management practices. Seeds were collected at the harvest maturity and shade dried to $12-14 \%$ of moisture content.

\section{Analysis of grains for physical and physicochemical properties}

Seed samples of $150 \mathrm{~g}$ were dehulled using a Satake dehusking machine, THU 358 and polished to a level of $8 \pm 2 \%$ of bran removal using a Satake polishing machine, THO 50 . 
Milling properties were determined according to the method described by Khush et al. (2000).

$\begin{array}{lll}\text { Husk } \% & =\frac{\text { Weight of hull }}{\text { Weight of rough rice }} \times 100 \% \\ \text { Total milled rice } \% & = \\ \text { Head grain } \% & \frac{\text { Weight of milled rice }}{\text { Weight of rough rice }} \times 100 \% \\ & =\frac{\text { Weight of head rice }}{\text { Weight of rough rice }} \times 100 \%\end{array}$

Length and breadth of milled rice kernel were measured using a micrometer and size and shape was classified according to the method described by Cruz \& Khush (2000) and IRRI standards. Volume expansion ratio was calculated by measuring the volumes of raw and cooked rice. Milled rice $(10 \mathrm{ml})$ was cooked in a beaker in a boiling water bath until rice grains were completely gelatinized. Volume of cooked rice was measured by measuring water displacement in a measuring cylinder. Gelatinization Temperature (GT) was determined by alkali digestibility test and according to the alkali spreading value (Cruz \& Khush, 2000).

Amylose content was estimated by the simplified procedure reported by Juliano, 1971 . Ground milled rice sample weighing $100 \mathrm{mg}$ (sieved mesh size 60) was put into $100 \mathrm{ml}$ volumetric flask and $1 \mathrm{ml}$ of $95 \%$ ethanol and $9 \mathrm{ml}$ of $1 \mathrm{~N}$ Sodium hydroxide was added. The content was heated in a boiling water bath to gelatinize starch, allowed to cool for one hour and mixed well by adding distilled water up to the volume. Starch solution $(5 \mathrm{ml}), 1 \mathrm{ml}$ of $1 \mathrm{~N}$ acetic acid and $2 \mathrm{ml}$ of iodine solution were added to a $100 \mathrm{ml}$ volumetric flask and the volume was made up with distilled water. Contents are shaken well and let stand for 20 minutes. The absorbance was measured at $620 \mathrm{~nm}$ using JENWAY 6305 Spectrophotometer.

Gel consistency was determined by the procedure described by Khush et al. (2000), with some modifications. Fine powdered rice flour $(100 \mathrm{mg})$ was weighed in a culture tube and $0.2 \mathrm{ml} 95 \%$ ethyl alcohol containing $0,025 \%$ Thymol blue and $2 \mathrm{ml}$ of $0.2 \mathrm{~N} \mathrm{KOH}$ were added. Contents were mixed using a Vortex mixer and covered tubes were kept in a boiling water bath for 8 minutes. The basic procedure described by Khush et al. (2000) was followed but the content was mixed twice at one minute intervals using a Vortex mixer to prevent coagulation of starch while cooking the samples in a boiling water bath. Thereafter, the contents were let stand at room temperature for 5 minutes and cooled in an ice water bath for 20 minutes. Tubes were laid horizontally on a graphing paper and the length of the gel was measured.

\section{Data analysis}

Amylose content, volume expansion and gel consistency were statistically tested using SAS statistical software. Ratios were analyzed using logarithmic transformation and percentage data were analyzed by Arcsin transformation. Alkali Spread Value data were analyzed by non-parametric Friedman test using MINITAB statistical software. Correlation analysis was conducted among the tested characteristics. 


\section{RESULTS AND DISCUSSION}

Brown rice percentage varied from $77-80 \%$ while the percentage of husk varied between 20 $23 \%$ which was within the range acceptable for commercial production. Generally husk contributes $20-22 \%$ of rough rice, although variation of $18-26 \%$ has been recorded (Cruz \& Khush, 2000). Although head rice percentage of many varieties ranged from 55-73\%, variety Kuruluthuda gave a head rice percentage of $41 \%$. (Table 1)

Table 1. Variation of milling quality parameters of different traditional rice varieties in Sri Lanka

\begin{tabular}{lcccccc}
\hline \multicolumn{1}{c}{ Variety } & $\begin{array}{c}\text { Accessi } \\
\text { on No. }\end{array}$ & $\begin{array}{c}\text { Brown } \\
\text { Rice }(\boldsymbol{\%})\end{array}$ & $\begin{array}{c}\text { Husk } \\
(\boldsymbol{\%})\end{array}$ & $\begin{array}{c}\text { Total } \\
\text { Milled Rice } \\
(\boldsymbol{\%})\end{array}$ & $\begin{array}{c}\text { Head } \\
\text { Grain }(\boldsymbol{\%})\end{array}$ & $\begin{array}{c}\text { Broken } \\
\text { Grain } \\
(\boldsymbol{\%})\end{array}$ \\
\hline Herath Banda & 280 & 79.7 & 20.3 & 74.1 & 73.1 & 1.0 \\
Kalu Heenati & 333 & 78.5 & 21.5 & 72.2 & 55.3 & 16.9 \\
Wanni Dahanala & 591 & 78.8 & 21.2 & 71.5 & 68.4 & 3.1 \\
Pachchaperumal & 799 & 79.8 & 20.2 & 73.5 & 71.8 & 1.7 \\
Suwandel & 579 & 78.5 & 21.5 & 73.4 & 72.4 & 1.0 \\
Madathawalu & - & 79.0 & 21.0 & 73.0 & 70.9 & 2.1 \\
Pokkali & 809 & 79.1 & 20.9 & 72.9 & 70.7 & 2.2 \\
Mawee & 087 & 78.8 & 21.2 & 73.2 & 72.0 & 1.2 \\
Gonabaru & 028 & 77.8 & 22.2 & 71.4 & 66.7 & 4.7 \\
Rathal & 133 & 77.3 & 22.7 & 72.7 & 66.1 & 6.6 \\
Hondarawalu & 285 & 78.0 & 22.0 & 70.5 & 58.5 & 12.0 \\
Kahata Wee & 324 & 78.9 & 21.1 & 72.2 & 69.1 & 3.1 \\
Kuruluthuda & 069 & 78.0 & 22.0 & 69.4 & 41.1 & 28.3 \\
Deveraddiri & 243 & 79.0 & 21.0 & 72.0 & 70.6 & 1.4 \\
Suduru Samba & 903 & 77.1 & 22.9 & 72.1 & 70.9 & 1.2 \\
Sulai & 502 & 80.0 & 20.0 & 72.7 & 68.8 & 3.9 \\
Dikwee & 246 & 78.9 & 21.1 & 73.1 & 71.4 & 1.7 \\
Sudu Heenati & 491 & 79.2 & 20.8 & 73.0 & 68.8 & 4.2 \\
Masuran & 086 & 78.2 & 20.8 & 71.4 & 67.6 & 3.8 \\
Inginimitiya & - & 80.0 & 20.0 & 73.8 & 71.1 & 2.7 \\
Dular & - & 77.8 & 22.2 & 72.0 & 63.8 & 8.2 \\
\hline
\end{tabular}

The highest kernel length was $5.98 \mathrm{~mm}$ in Sudu Heenati and minimum of $3.6 \mathrm{~mm}$ for Suwandel. Kernel length of many varieties varied between $5-6 \mathrm{~mm}$ while the kernel breadth varied between $2-2.5 \mathrm{~mm}$ except Suwandel, Rathal and Suduru Samba which are short grained varieties. Varieties Dik Wee and Inginimitiya showed a length width ratio over 3 which considered as slender in shape. When the length $(<6 \mathrm{~mm})$ is considered those varieties were categorized under the medium length class (Table 2). Consumer affinity to size and shape is highly variable. Most of the varieties (other than Suwandel, Gonabaru, Rathal, Suduru samba, Inginimitiya and Dular) were consisted of red pericarp. 
Table 2. Variation of physical properties of selected traditional rice varieties in Sri Lanka

\begin{tabular}{|c|c|c|c|c|c|c|c|}
\hline Variety & $\begin{array}{c}\text { Accession } \\
\text { No. }\end{array}$ & Length & $\begin{array}{c}\text { Size } \\
\text { Class }\end{array}$ & $\begin{array}{c}\text { Widt } \\
\text { h }\end{array}$ & $\mathrm{L} / \mathrm{W}$ ratio & $\begin{array}{l}\text { Grain } \\
\text { Shape }\end{array}$ & Colour \\
\hline Herath Banda & 280 & 5.47 & Short & 2.27 & 2.41 & Medium & Red \\
\hline Kalu Heenati & 333 & 5.15 & Short & 2.16 & 2.38 & Medium & Red \\
\hline Wanni Dahanala & 591 & 5.41 & Short & 2.29 & 2.36 & Medium & Red \\
\hline Pachchaperumal & 799 & 5.22 & Short & 2.34 & 2.23 & Medium & Red \\
\hline Suwandel & 579 & 3.69 & Short & 1.80 & 2.05 & $\begin{array}{l}\text { Medium/ } \\
\text { Bold }\end{array}$ & White \\
\hline Madathawalu & - & 5.62 & Medium & 2.26 & 2.49 & Medium & Red \\
\hline Pokkali & 809 & 5.60 & Medium & 2.22 & 2.52 & Medium & Red \\
\hline Mawee & 087 & 5.64 & Medium & 2.14 & 2.64 & Medium & Red \\
\hline Gonabaru & 028 & 5.16 & Short & 1.98 & 2.61 & Medium & White \\
\hline Rathal & 133 & 3.76 & Short & 1.93 & 1.95 & Bold & White \\
\hline Hondarawalu & 285 & 5.06 & Short & 2.29 & 2.21 & Medium & Red \\
\hline Kahata Wee & 324 & 5.63 & Medium & 2.34 & 2.41 & Medium & Red \\
\hline Kuruluthuda & 069 & 5.20 & Short & 2.40 & 2.17 & Medium & Red \\
\hline Deveraddiri & 243 & 5.45 & Short & 2.58 & 2.11 & Medium & Red \\
\hline Suduru Samba & 903 & 3.90 & Short & 1.48 & 2.64 & Medium & White \\
\hline Sulai & 502 & 5.31 & Short & 2.29 & 2.32 & Medium & Red \\
\hline Dik Wee & 246 & 5.51 & Medium & 1.74 & 3.17 & Slender & Red \\
\hline Sudu Heenati & 491 & 5.98 & Medium & 2.14 & 2.79 & Medium & Red \\
\hline Masuran & 086 & 3.89 & Short & 2.27 & 1.71 & Bold & Red \\
\hline Inginimitiya & - & 5.78 & Medium & 1.7 & 3.40 & Slender & White \\
\hline Dular & - & 5.38 & Short & 2.12 & 2.54 & Medium & White \\
\hline
\end{tabular}

Volume Expansion (VE) over cooking was taken as the ratio between volume of cooked rice and initial volume of raw rice. Volume expansion values of selected varieties were varied form a maximum of 3.3 in Deveraddiri and minimum of 2.5 in Wanni Dahanala (Table 3). However, a significant difference was not observed in VE values.

Amylose content (AC) is the major determinant of the eating quality of rice (Juliano, 1971). It negatively correlates with cohesiveness, tenderness, colour and gloss of boiled rice (Cruz \& Khush, 2000). Volume expansion and amylose content show more genetic variation than other traits (Singh et al., 2000). Amylose content of the evaluated varieties varied from the lowest of $17.63 \%$ in Suduru Samba and highest of 27.14\% in Herath Banda. Both highest and lowest $\mathrm{AC}$ values showed a significant difference $(\mathrm{p}<0.05)$ compared to other AC values. Majority of the evaluated varieties falls into intermediate AC category (between 20$25 \%$ ), which was characterized by non-waxy, non-glutinous rice that cooks moist and tender, 
and does not become hard upon cooking, hence preferred by consumers (Rohilla et al., 2000). Only the variety Suduru Samba could be clearly categorized under the low amylose group. Varieties Pachcaperumal and Maa Wee recorded $19.44 \%$ and $19.04 \%$ AC values respectively and therefore, fall in low amylose group (AC values between 10-20\%) but more closer to the intermediate group (Table 3).

The recorded AC values of some varieties show some deviations (lower values) compared to the values found in the literature (Wickramasinghe and Noda, 2008, Rajapakse et al., 2011), possibly it may be due to the high ambient temperature prevailed during the ripening stage of the crop. In general, temperature correlates negatively with amylose content. According to Cruz et al. (1989), amylose content decreases with increasing temperature (Rohilla et al. 2000). Maximum temperature between $24.1{ }^{0} \mathrm{C}-29.6{ }^{0} \mathrm{C}$ was observed at Bathalagoda during the ripening stage.

Although amylose content is the major determinant of eating quality, it usually accounts for no more than $65 \%$ of the differences in eating quality of rice (Juliano, 1971). Gel consistency (GC) is another major character responsible for the texture of cooked rice. In general, rate of hardening of cooked rice and differences in hardness of cooked rice correlate with gel consistency. Intermediate and low amylose rice usually have soft gel consistency and preferred over hard gel consistency (Rohilla et al., 2000)

Rice varieties Herath Banda, Wanni dahanala, Pokkali, Hondarawalu, Kuruluthuda, Deveraddiri and Sulai were identified to have soft gel consistency and GC values of these varieties were significantly different $(\mathrm{p}<0.05)$ from the $\mathrm{GC}$ of the other varieties (Table 3 ). Although GC $<4 \mathrm{~cm}$ is categorized under the GC category "hard", and GC $=4-6 \mathrm{~cm}$ is categorized under "intermediate", there were no significant differences observed among those GC values.

When correlation analysis was performed among the tested characteristics, GC was observed to have a positive correlation with AC (Table 4). According to Cruz \& Khush (2000), varietal differences in gel consistency exists among varieties having similar amylose contents. In contrast, amylose content was reported to have significantly negative correlation with gel consistency indicating that simultaneous quality traits can be made with selection of either one but not both of them (Singh et al., 2000). Gel consistency has recorded a negative correlation with Alkali Spread Value (ASV) that indicates a positive correlation with gelatinization temperature. Gelatinization temperature (GT) is an indicator of the time required for cooking and it is the range temperature wherein at least $90 \%$ of the starch granules swell irreversibly in hot water with loss of crystallinity and birefringence (Cruz and Khush, 2000). Also GT affects water uptake, volume expansion and kernel elongation (Singh et al., 2000).

Most of the selected traditional varieties fall into intermediate gelatinization temperature category $\left(70-74{ }^{\circ} \mathrm{C}\right)$ as indicated by the ASV of 4 and 5. Some varieties; Kalu Heenati, Madathawalu, Pokkali, Mawee, Gonabaru, Inginimitiya and Dular showed low GT values between 55 to $69{ }^{\circ} \mathrm{C}$ indicated by ASV of 6 and 7. Only Kuruluthuda recorded highintermediate GT value, indicated by ASV of 3 and none of the varieties recorded high GT values $\left(>75^{\circ} \mathrm{C}\right)$ indicated by ASV of 1 and 2 . 
Table 3. Variation of physicochemical properties of selected traditional rice varieties in Sri Lanka

\begin{tabular}{llllllll}
\hline \multicolumn{1}{c}{ Variety } & $\mathbf{V E}$ & Abs. & AC $(\mathbf{\%})$ & GC $(\mathbf{c m})$ & GC class & ASV & GT class \\
\hline Herath Banda & $2.7 \mathbf{a b}$ & 0.3750 & $27.14 \mathbf{a}$ & $7.85 \mathbf{a}$ & Soft & 5 & Intermediate \\
Kalu Heenati & $3.0 \mathbf{a b}$ & 0.3575 & $25.88 \mathbf{a b}$ & $3.80 \mathbf{b}$ & Hard & 6 & Low \\
Wanni Dahanala & $2.5 \mathbf{b}$ & 0.3225 & $23.34 \mathbf{c}$ & $8.15 \mathbf{a}$ & Soft & 5 & Intermediate \\
Pachchaperumal & $2.7 \mathbf{a b}$ & 0.2685 & $19.44 \mathbf{~ e f g}$ & $3.50 \mathbf{b}$ & Hard & 5 & Intermediate \\
Suwandel & $3.1 \mathbf{a}$ & 0.2780 & $20.12 \mathbf{d e f}$ & $3.50 \mathbf{b}$ & Hard & 5 & Intermediate \\
Madathawalu & $2.7 \mathbf{a b}$ & 0.3350 & $24.25 \mathbf{b c}$ & $4.10 \mathbf{b}$ & Medium & 6 & Low \\
Pokkali & $2.8 \mathbf{a b}$ & 0.3225 & $23.34 \mathbf{c}$ & $7.30 \mathbf{a}$ & Soft & 6 & Low \\
Mawee & $3.0 \mathbf{a b}$ & 0.2630 & $19.04 \mathbf{f g}$ & $4.15 \mathbf{b}$ & Medium & 6 & Low \\
Gonabaru & $3.0 \mathbf{a b}$ & 0.3025 & $21.90 \mathbf{c d}$ & $3.50 \mathbf{b}$ & Hard & 7 & Low \\
Rathal & $3.2 \mathbf{a}$ & 0.3000 & $21.72 \mathbf{c d e}$ & $3.65 \mathbf{b}$ & Hard & 4 & Intermediate \\
Hondarawalu & $3.0 \mathbf{a b}$ & 0.3120 & $22.58 \mathbf{c d}$ & $7.75 \mathbf{a}$ & Soft & 5 & Intermediate \\
Kahata Wee & $2.9 \mathbf{a b}$ & 0.3195 & $23.13 \mathbf{c}$ & $3.65 \mathbf{b}$ & Hard & 5 & Intermediate \\
Kuruluthuda & $2.6 \mathbf{a b}$ & 0.3175 & $22.98 \mathbf{c}$ & $9.00 \mathbf{a}$ & Soft & 3 & High/ \\
& & & & & & & Intermediate \\
Deveraddiri & $3.3 \mathbf{a}$ & 0.3090 & $22.37 \mathbf{c d}$ & $7.25 \mathbf{a}$ & Soft & 5 & Intermediate \\
Suduru Samba & $2.9 \mathbf{a b}$ & 0.2435 & $17.63 \mathbf{g}$ & $3.40 \mathbf{b}$ & Hard & 5 & Intermediate \\
Sulai & $2.9 \mathbf{a b}$ & 0.3200 & $23.16 \mathbf{c}$ & $8.25 \mathbf{a}$ & Soft & 4 & Intermediate \\
Dik Wee & $2.8 \mathbf{a b}$ & 0.3325 & $24.07 \mathbf{b c}$ & $3.65 \mathbf{b}$ & Hard & 5.5 & Intermediate \\
Sudu Heenati & $2.8 \mathbf{a b}$ & 0.3170 & $22.95 \mathbf{c}$ & $4.00 \mathbf{b}$ & Hard & 5 & Intermediate \\
Masuran & $2.7 \mathbf{a b}$ & 0.3195 & $23.13 \mathbf{c}$ & $3.65 \mathbf{b}$ & Hard & 4 & Intermediate \\
Inginimitiya & $2.9 \mathbf{a b}$ & 0.3090 & $22.37 \mathbf{c d}$ & $4.95 \mathbf{b}$ & Medium & 6 & Low \\
Dular & $2.9 \mathbf{a b}$ & 0.3095 & $22.40 \mathbf{c d}$ & $5.30 \mathbf{b}$ & Medium & 6 & Low \\
\hline
\end{tabular}

\footnotetext{
VE - -Volume expansion (Mean value)

Abs. - Absorbance at 620nm (Mean value)

AC - Amylose content (Mean value)

GC - Gel consistency (Mean value)

ASV - Alkali spread value (Median value)

GT - Gelatinization temperature
}

Table 4. Correlation coefficients among tested physicochemical properties of selected traditional rice varieties

\begin{tabular}{lccc}
\hline & Amylose content & Volume expansion & Gel consistency \\
\hline Alkali spread value & 0.04 & 0.15 & $-0.35^{*}$ \\
Amylose content & & -0.22 & $0.32^{*}$ \\
Volume expansion & & & -0.16 \\
\hline "Indicates significance at $\mathrm{P}<0.05$ level. & &
\end{tabular}

\section{CONCLUSION}

All the evaluated rice varieties except Herath Banda and Kalu Heenati fall into intermediate or low amylose categories which are preferred by consumers and among them, Wanni Dahanala, Pokkali, Hondarawalu, Kuruluthuda, Deveraddiri and Sulai contain soft gel consistency which is again a preferred character. Gelatinization temperatures show intermediate or low values in all the tested varieties except for Kuruluthuda. Milling quality 
also was within the acceptable range except in Kuruluthuda which was recorded a low percentage of head rice.

When considered the overall quality, Wanni Dahanala, Pokkali, Hondarawalu, Deveraddiri and Sulai can be considered to have high physical and physiochemical qualities among the tested varieties. The information generated herein can be utilized in rice variety improvement programmes and in selecting suitable traditional rice varieties for commercial cultivation.

\section{ACKNOWLEDGEMENT}

Financial assistance received by National Research Council trough grant NRC-11-86 is highly acknowledged. Sincere appreciation goes to Ms. R.J. Rathnayake, Ms. D.K. Padmalatha, Ms. K.M. Kumarihami and Ms. M.A.H. Priyangika, Rice Research and Development Institute, Bathalagoda for their contribution in field and laboratory works. Authors also wish to thank Ms. C. Piyasiri for assistance in statistical analysis.

\section{REFERENCES}

Abesekara, W.K.S.M., Somasiri, H.P.P.S., Premakumara, G.A.S., Benthota, A.P., Rajapakse, D. and Ediriweera N. (2008). Cooking and eating quality traits of some Sri Lankan traditional rice varieties across Yala and Maha seasons: Tropical Agriculture Research. 20, 168 - 176.

Abesekara, W.K.S.M., Premakumara, G.A.S., Rathnasooriya, W.D. and Chandrasekaran, N.V. (2013). Antioxidant properties of some Sri Lankan traditional red rice (Oryza sativa L.). Available at

http://www.cmb.ac.lk/anual-research-symposium/anual-research-symposium Science/ant...

Abeywickrama, A.S.M.T., Gunadasa, A.H., Abeysekara, S.W., Hemachandra, P.V. and Pathinayake, B.D. (2010). Rice variety improvement in Sri Lanka: progress achieved and vision for the future. Rice Congress at Plant Genetic Resources Center, Gannoruwa, Sri Lanka. 2-3 December, 2010. p: 9.

Cruz N.D. and Kush G.S. (2000). Rice grain quality evaluation procedures. pp15-28. In: Sing, R.K., Sing, U.S. and Khush, G.S. (Ed.). Aromatic rices. Oxford and IBH Publishing Co. Pvt. Ltd. New Delli, India

Grain storage techniques - Evolution and trends in developing countries. Quality characteristics of grains. Available at http://www.fao.org/docrep/x5048e/x5048e03.htm

Juliano, B.O. (1971). “A simplified assay for milled rice amylose”. Cereal Science Today. 16, 334 - 338 . 
Rajapakse, D., Benthota, A.P., Wijesundara, S.M., Premakumara, G.A.S. and Herath, T. (2011). Properties of some traditional rice varieties of Sri Lanka. Industrial Technology institute and Department of Agriculture, Sri Lanka. p 61.

Rice Knowledge Bank: Procedures for Measuring quality of milled rice. Available at http://www.knowledgebank.irri.org/rkb/quality-characteristics-of-milled-rice/procedures-formeasuring-quality-of-milled-rice.html

Rohilla, R., Singh, V.P., Singh U.S., Singh R.K. and Khush G.S. (2000). Crop husbandry and environmental factors affecting aroma and other quality traits. pp 201-216. In: Sing, R.K., Sing, U.S. and Khush, G.S. (Ed.). Aromatic rices. Oxford and IBH Publishing Co. Pvt. Ltd. New Delli, India

Samarasinghe, W.L.G., Abeywickrama, A.S.M.T. and Jayasekara, A. (2010). Biotechnology applications in rice breeding in Sri Lanka. Rice Congress at Plant Genetic Resources Center, Gannoruwa, Sri Lanka. 2-3 December, p: 11.

Singh, R.K., Gautam, P.L., Saxena, S. and Singh, S. (2000). Scented rice germplasm conservation, evaluation and utilization. pp 107-133. In: Sing, R.K., Sing, U.S. and Khush, G.S. (Ed.). Aromatic rices. Oxford and IBH Publishing Co. Pvt. Ltd. New Delli, India

Wickramasinghe, H.A.M. and Noda, T. (2008). Physicochemical properties of starches from Sri Lankan rice varieties. Food Science and Technology Research, 14(1), pp 49 - 54. 